\title{
Characteristics of Students Sensory Mathematical Imagination in Solving Mathematics Problem
}

\author{
Teguh Wibowo ${ }^{a}$, Akbar Sutawidjaja $^{\mathrm{b}}$, Abdur Rahman As’aric, I Made \\ Sulandrad
}

aMuhammadiyah University of Purworejo, INDONESIA; 'State University of Malang, INDONESIA; 'State University of Malang, INDONESIA; 'State University of Malang, INDONESIA

ABSTRACT

This study aim to investigate the characteristics of students' sensory mathematical imagination of in solving mathematics problems. This study includes qualitative research with two students of VIII grade junior high school used as subjects. To determine the characteristics of students sensory mathematical imagination who appeared in solving mathematics problems, researchers use the problem sheet as a supporting instrument in this study. The problem sheet consists of a question item that serves to stimulate appear of students sensory mathematical imagination. For accuracy of data using triangulation method of observation, students answers, and interviews. The results showed characteristics of students sensory mathematical imagination in solving mathematics problems is appear of the idea based on perception due to stimulate of the problem, actualization information by analogy according to what people think, the activity involves body movement (sensory motor), can be seen through visual representation.

KEYWORDS

Perception; sensory mathematical imagination
ARTICLE HISTORY

Received 15 September 2016 Revised 10 November 2016 Accepted 27 February 2017

\section{Introduction}

Research related to imagination in learning mathematics ever done by Wilke (2010), Chapman (2008), and Nemirovsky \& Ferrara (2008). The results showed the importance of mathematical imagination in solving mathematics problems can help students develop their thinking. Similarly, research Swirski (2010), Samli (2011), Kotsopoulos \& Cordy (2009), van Alphen (2011), shows the results of these studies strongly support the involvement of imagination in

\section{CORRESPONDENCE T. Wibowo $\square$ teguhwibowo743@gmail.com}

(c) 2017 T. Wibowo et al.

Open Access terms of the Creative Commons Attribution 4.0 International License apply. The license permits unrestricted use, distribution, and reproduction in any medium, on the condition that users give exact credit to the original author(s) and the source, provide a link to the Creative Commons license, and indicate if they made any changes. (http://creativecommons.org/licenses/by/4.0/) 
learning. Without imagination, anyone can not imagine an event in history or verbal problem in mathematics (van Alphen, 2011).

Samli (2011) says, imagination is ability to form images and ideas about things never seen or experienced before. While van Alphen (2011) considers imagination as ability of the mind to evoke a mental picture of what is not present, they experience as if they were real. In this case, imagination is ability of the mind which serves to form an image or certain ideas. So mathematical imagination in this research is ability of the mind to form ideas in solving mathematics problems. The based assumption is when students in face of mathematics problem, mathematical imagination can help thinking of students in finding solution ideas to solving the problem.

Wibowo \& As'ari (2014) divides three types of students mathematical imagination in solving mathematics problem, namely sensory mathematical imagination, creative mathematical imagination, and recreative imagination mathematical. Sensory imagination basically is perception such as the stimulation of problem (Currie \& Ravenscroft, 2002). From perception can appear of idea for solving mathematics problems. This idea is a form of imagination that is appeared by students. Wibowo \& As'ari (2014) said, sensory mathematical imagination can be seen through appear of the idea based on perception after receiving stimuli of the problem. How characteristics of students sensory mathematical imagination in solving mathematics problems? In this paper will describe characteristics one type of mathematical imagination namely sensory mathematical imagination. So the aim of this study to determine characteristics of students sensory mathematical imagination in solving mathematics problem.

\section{Research Methods}

This study used a qualitative approach. A qualitative approach was chosen because it fits the characteristics possessed, ie scientific environment, researchers as a key instrument, qualitative methods, inductive data analysis, design develops and nature interpretation (Creswell, 2014). The object of research is characteristics of students sensory mathematical imagination in solving mathematics problem. The subjects were 2 students of VIII grade junior high school were taken by considering students ability in solving mathematics problem sheet. Problem sheet consists of a question item that serves to explore appear of students sensory mathematical imagination. Here problem sheet is used in this study.

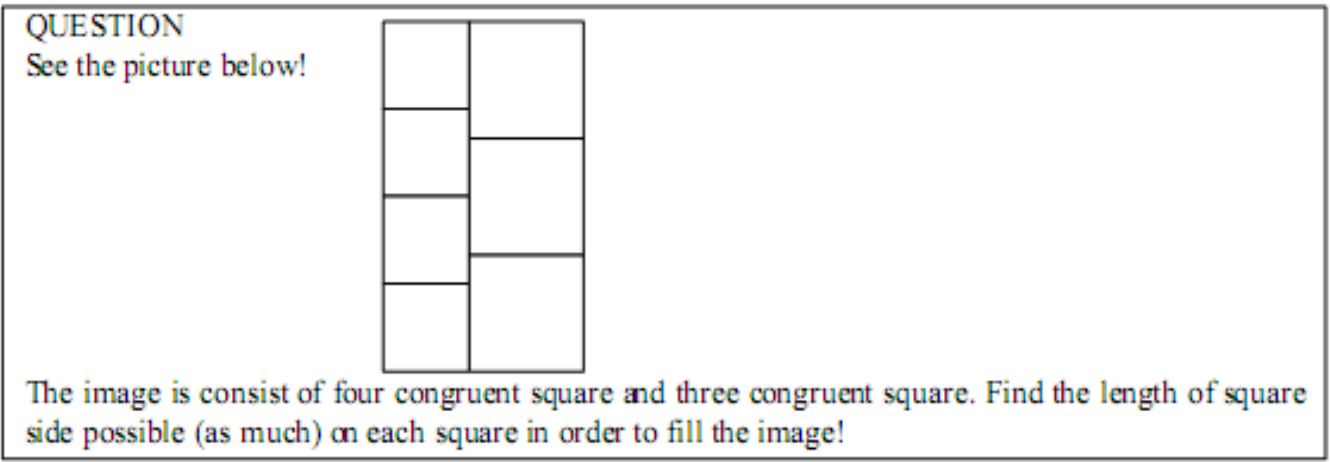

Figure 1. Problem Research 
The data collection technique using answer sheet of test, observation and interviews. The data collected in this study a descriptive data were then analyzed by inductively. Analysis of data using qualitative analysis techniques developed by Creswell (2014), which includes reducing data, presenting data, and draw conclusions. For accuracy of data using triangulation techniques ie observation, students answers, and interviews.

\section{Research Result}

Analysis characteristics of students sensory mathematical imagination assessed based on appear of students sensory mathematical imagination in solving problem. Here's exposure data and analysis appear of students sensory mathematical imagination in each subject.

Analysis Appear of Sensory Mathematical Imagination in Subject 1 (S1)

S1 started to work on the problems with reading the question with think aloud for 80 seconds. S1 then moving the fingers over the matter, it indicates subject tried to examine and understand the question. This activity lasted for 120 seconds, but subject has not been able to understand the question. It is seen $\mathrm{S} 1$ repeat to reading the question for getting information, corresponding to statement following subjects.

$\mathrm{S} 1$ : The length is not known.

Subjects were informed that the length of each square on the matter is not known. From this information then $\mathrm{S} 1$ see images more carefully in order to obtain information:

$\mathrm{S} 1$ : The length of four small square sides equal to the length of three large square sides.

Subjects can know that the length of four small square sides equal to the length of three large square sides by drawing square contained in the matter. It shows $\mathrm{S} 1$ has been able to understand the intent of the question.

Furthermore S1 trying to find the solution of the problem. S1 moving the fingers on the table, it shows subject uses his thinking process to find the solution of the problem. This activity lasted for 70 seconds, then subject says:

$\mathrm{S} 1$ : The length of all 12.

Subject inferred the length side of all square is $12 \mathrm{~cm}$. Although subject can determine the length side of all square $12 \mathrm{~cm}$, but subject look still difficulties in determining the length side of each square. After contemplate a moment, subjects have perception that the length side of small square $3 \mathrm{~cm}$ and large square $4 \mathrm{~cm}$. This is consistent with statement of subject:

$\mathrm{S} 1$ : The length of small square $3 \mathrm{~cm}$ and large square $4 \mathrm{~cm}$.

This idea appear on based subject perception after received stimulus of the problem in question. Stimulus is the order in the matter to determine the length side of each square that fill the image. These stimulus arising to subject perception which then appear the idea to determine the length of each side of square. This idea is a form of students mathematical imagination in facing of such problems or so-called sensory mathematical imagination. This is reinforced by the answers of subject that demonstrate this. 


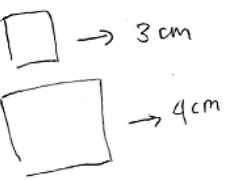

Figure 2. S1 Drawing of Square With the Length

As confirmed why subject determines the length side of small square $3 \mathrm{~cm}$ and large square $4 \mathrm{~cm}$, subject is not able to disclose the reason. This reinforces the notion that sensory mathematical imagination is closely linked to perception of student. To reinforce this case the researcher $(\mathrm{P})$ conducted interviews with subject:

\section{$\mathrm{P}:$ Why is $3 \mathrm{~cm}$ and $4 \mathrm{~cm}$, instead of $3 \mathrm{~cm}$ and $5 \mathrm{~cm}$ ? \\ $\mathrm{S} 1$ : Silently.}

Subject is not able to disclose the reasons why choosing the length side of square $3 \mathrm{~cm}$ and $4 \mathrm{~cm}$ not others. This indicates that subject determines the length side of square $3 \mathrm{~cm}$ and $4 \mathrm{~cm}$ is perception by looking at relationship between total length of $12 \mathrm{~cm}$ with the length of each square.

Above description shows $\mathrm{S} 1$ is able to appears of sensory mathematical imagination in solving the problem, but can not appear another type of mathematical imagination. Structure of sensory mathematical imagination processes $\mathrm{S} 1$ can be illustrated in the diagram below. 


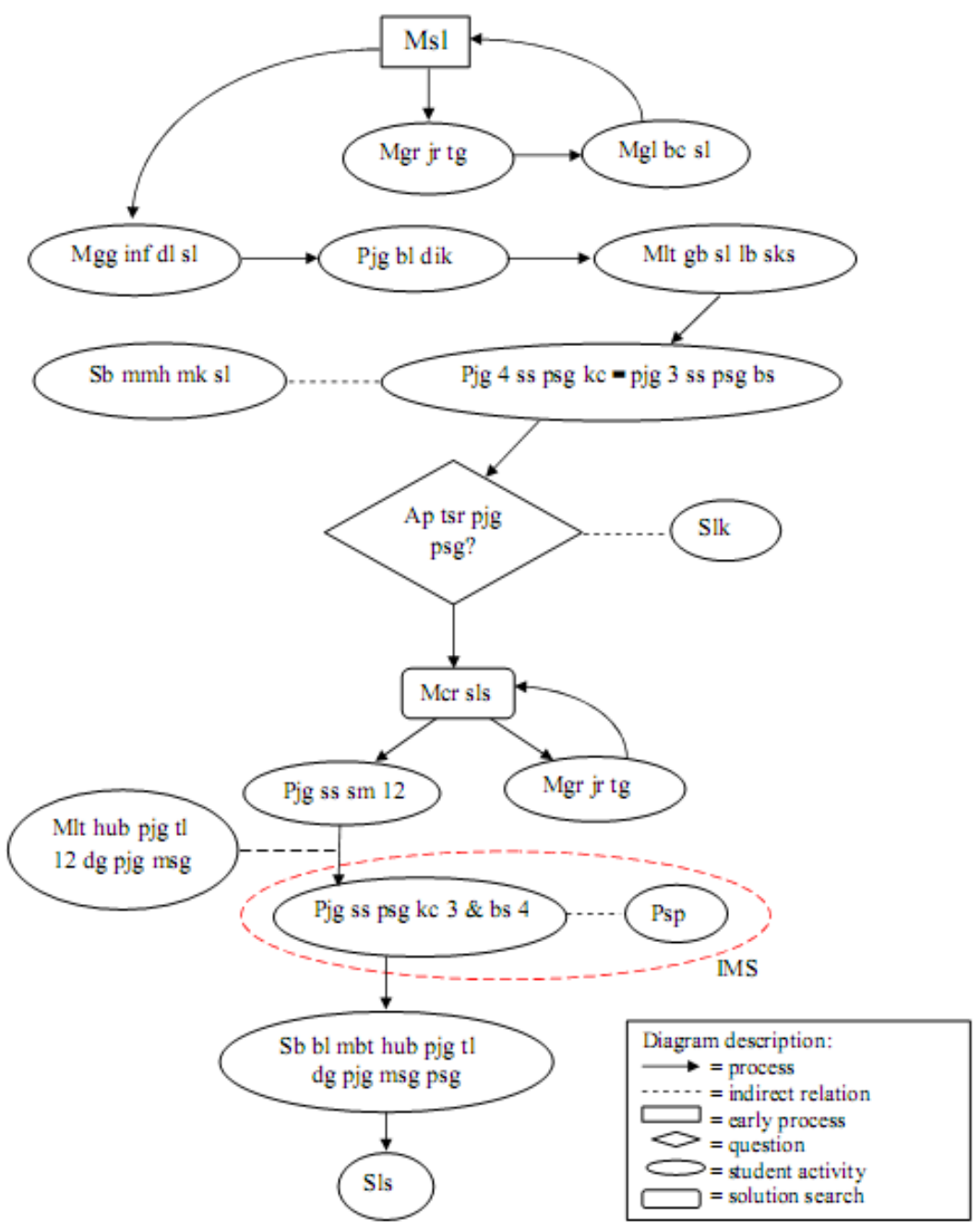

Diagram 1. Process Appear of Sensory Mathematical Imagination S1

Table 1. Term Code Process of Mathematical Imagination S1

\begin{tabular}{ll}
\hline \multicolumn{1}{c}{ Term } & \multicolumn{1}{c}{ Code } \\
\hline Problem & Msl \\
\hline Moving the fingers & Mgr jr tg \\
\hline Repeating reading the matter & Mgl bc sl \\
\hline Digging information in the question & Mgg inf dl sl \\
\hline The length unknown & Pjg bl dik \\
\hline Seeing pictures of the matter more carefully & Mlt gb sl lb sks \\
\hline Length 4 side of small square = length 3 sides of large square & Pjg 4 ss psg kc = pjg 3 ss psg \\
& bs \\
\hline Subject able to understand of intent the matter & Sb mmh mk sl \\
\hline Do up the length of square sir? & Ap tsr pjg psg? \\
\hline Please & Slk \\
\hline Finding solutions & Mcr sls \\
\hline Moving the finger & Mgr jr tg \\
\hline The length side of all 12 & Pjg ss sm 12 \\
\hline See relationship between total length of 12 cm with the length of & Mlt hub pjg tl 12 dg pjg msg \\
each square & psg \\
\hline The length side of small square $3 \mathrm{~cm}$ and large square $4 \mathrm{~cm}$ & Pjg ss psg kc 3 \& bs 4 \\
\hline
\end{tabular}




\begin{tabular}{ll}
\hline Perception & Psp \\
\hline Sensory mathematical imagination & IMS \\
\hline $\begin{array}{l}\text { Subject has not been able to make a more distant relationship } \\
\text { between total length with the length of each square }\end{array}$ & Sb bl mbt hub pjg tl dg pjg \\
\hline Finished & Sls psg \\
\hline
\end{tabular}

\section{Analysis Appear of Sensory Mathematical Imagination in Subject 2 (S2)}

S2 begin work on the problem and read aloud for 70 seconds. S2 redoing read the problem to understand intent of the problem. After a while S2 to make a square on the answer sheet as an image problem with a large size. Then S2 make the lines on the image horizontally or vertically. The images obtained looks like this:

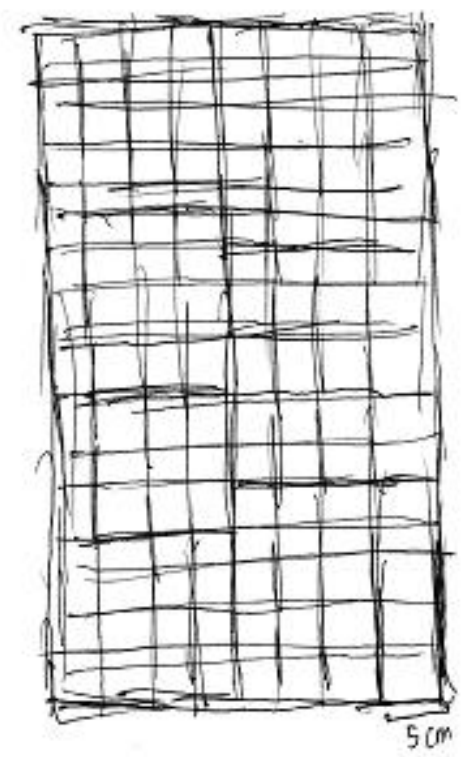

Figure 3. The Square Image that done S2

Then the researcher questioned on subject:

$\mathrm{P}:$ How the length sides?

$\mathrm{S} 2: 5 \mathrm{~cm}$

Subjects have perception that the length side of small square is $5 \mathrm{~cm}$. Then the researcher ask further:

$\mathrm{P}$ : How can $5 \mathrm{~cm}$ ? Why not $3 \mathrm{~cm}$ ?

$\mathrm{S} 2$ : if $3 \mathrm{~cm}$ smallness.

This perception appear from the image be done by subject. Subjects did not link between the length of a small square with a large square that actually have different lengths. This perception such allegations of subject saying $3 \mathrm{~cm}$ too small. This perception appear due to the stimulation of issue in the problem to determine the length of square, that is equal to $5 \mathrm{~cm}$. This is a realization of sensory mathematical imagination produced by subject. Furthermore, the researcher ask:

$\mathrm{P}$ : How length sides of the small square and the large square?

$\mathrm{S} 2$ : The length of small square $5 \mathrm{~cm}$ and the length of large square $20 \mathrm{~cm}$. 
$\mathrm{P}:$ Why $20 \mathrm{~cm}$ ?

S2 : Because there are 4 square.

Subject suspect the length of one square is $20 \mathrm{~cm}$, which is subject say a big square. Each square divide into four a small square vertically and also horizontally (as shown in Figure 3). The small square has a length of $5 \mathrm{~cm}$, with reason that there are four small square that meets a length of $20 \mathrm{~cm}$. Although it looks quite logical, but this step is actually not right. Because two square image in question has a different size and length difference is not so great. Furthermore, the researcher asks:

\section{$\mathrm{P}$ : This is made of small squares for what purpose?}

S2: to fill the image.

Subject making small squares as shown in Figure 3 with the purpose to fill the image.

$\mathrm{P}:$ How as much as possible?

S2: Do not know.

Subjects do not know the length of square side as much as that in asking the question. Answer students when it appeared the length of square side $5 \mathrm{~cm}$ is a perception which is a form of students sensory mathematical imagination in solving the problem. The above description shows, S2 is able to appear sensory mathematical imagination in solving the problem, but can not appear another mathematical imagination. Flow appear of sensory mathematical imagination $\mathrm{S} 2$ can be illustrated in the diagram below. 


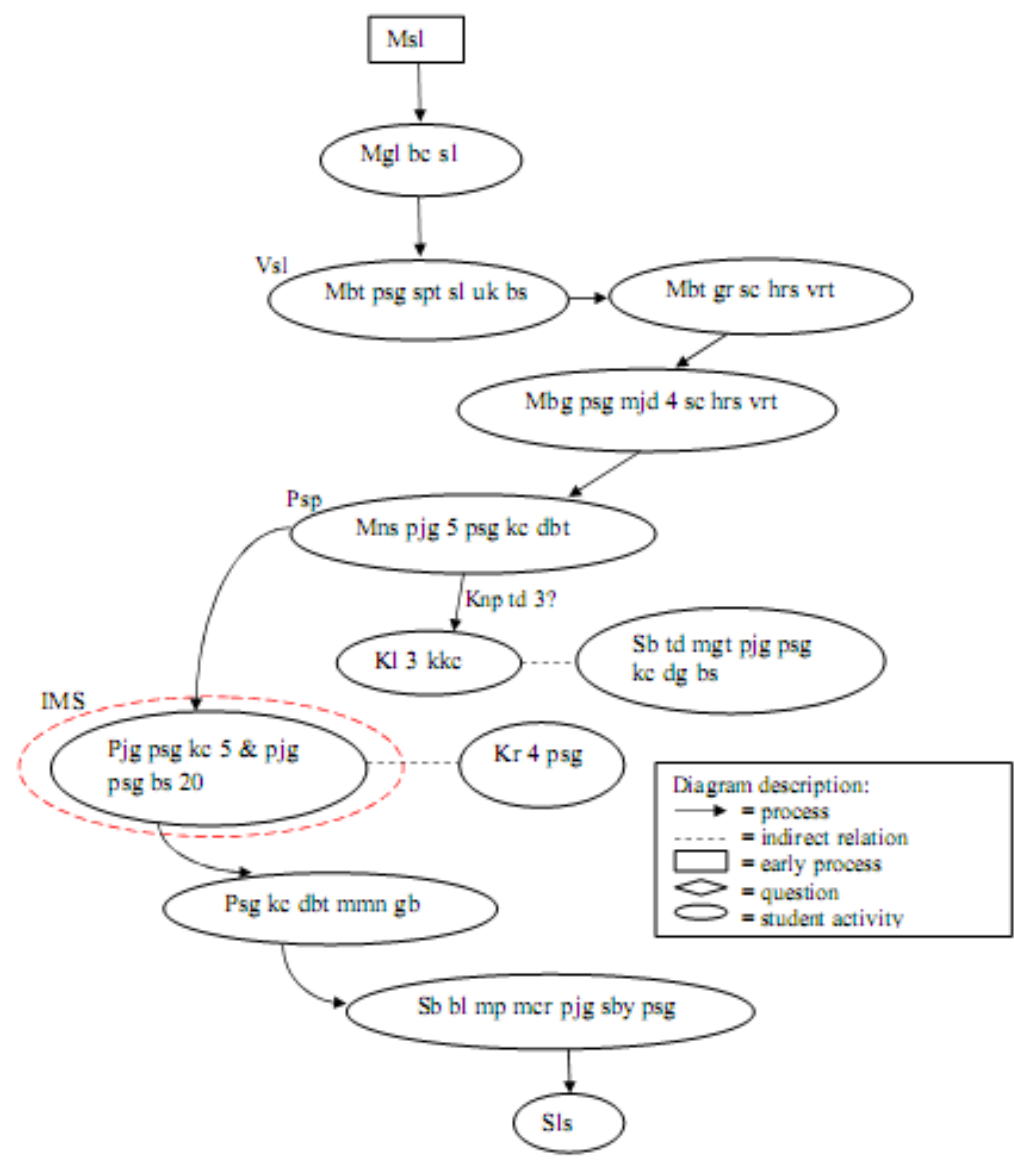

Diagram 2. Flow Appear of Mathematical Imagination S2

Table 2. Terms Code Process of Mathematical Imagination S2

\begin{tabular}{ll}
\hline Terms & Code \\
\hline Problem & Msl \\
\hline Repeat reading the problem & Mgl bc sl \\
\hline Make of square such the problem with great size & Mbt psg spt sl uk bs \\
\hline Visualization & Vsl \\
\hline Make of lines horizontally or vertically & Mbt gr sc hrs vrt \\
\hline Dividing each square into 4 square horizontally or vertically & Mbg psg mjd 4 sc hrs vrt \\
\hline Writing a length of $5 \mathrm{~cm}$ on a small square made & Mns pjg 5 psg kc dbt \\
\hline Perception & Psp \\
\hline Why not 3 cm & Knp td 3 \\
\hline If 3 cm smallness & Kl 3 kkc \\
\hline Subjects did not link between the length of small square with the length & Sb td mgt pjg psg kc dg \\
of large square & bs \\
\hline The length of small square 5 cm and large square $20 \mathrm{~cm}$ & $\begin{array}{l}\text { Pjg psg kc } 5 \text { \& pjg psg bs } \\
20\end{array}$ \\
\hline Sensory mathematical imagination & IMS \\
\hline Because there are four square & $\mathrm{Kr} 4$ psg \\
\hline Small squares made to fill the image & Psg kc dbt mmn gb \\
\hline Subject has not been able to search the length as many of the square & Sb bl mp mcr pjg sby psg \\
\hline Finished & Sls \\
\hline
\end{tabular}




\section{Discussion}

Sensory mathematical imagination in this study represented by subject ie S1 and S2 in solving mathematics problem. Sensory imagination related with students perception after receiving stimulation of the problem (Currie \& Ravenscroft, 2002). Through stimulation of the problem raises students perception related to the problem. This perception can appear of idea to solve the problem.

Appear of sensory mathematical imagination two subjects can be said is identical, ie subject started to read the questions and then repeat it and move your fingers to understand intent of the question. After reading the question and repeated it, subject digging information of the question. In the process of digging information, subject to do it in different ways. This is accordance with opinion of Muir, Beswick \& Williamson (2008), that in problem solving skills needed to interpret information in the question. In an effort to digging information, subject move the fingers on the table. This activity shows a subject using thinking skills to understand the purpose of the question. This motor activity can trigger students mathematical imagination in solving problem. It reinforced the opinion Nemirovsky \& Ferrara (2009) who said mathematical imagination involves body movement activity (sensory motor) to develop innovative students in solving mathematics problems. Subjects were then repeated the phrase "find the length of square side possible" to better understand intent of the question.

The next step that done of subject is draw a square as in the problem. Carroll, et al (2010) said through an image can decipher information by analogy according to what people think. Through this image then appeared subject perception to determine the length of square. S2 have perception that the length of small square side is 5 units, $\mathrm{S} 1$ have perception total length of all square is 12 units. Perception of subject appears due to stimulus of the problem. Stimulus is order in the problem to determine the length side of each square that meets the image. These stimulus induce subject perception to determine the length side of each square. Through perception appeared the idea for solving mathematics problems. Van Alphen (2011) said imagination appear from perception through the five senses. In other words, the picture and think aloud that done of student (eye \& ear sensory) can appeared perception that later appeared the idea to solve the problem. In this case the idea is appear of students in solving mathematics problem is a form of sensory mathematical imagination. On the other hand subjects also done a visual representation of idea based on perception that is appeared. Solso, et al (2008) said imagination can be seen through a visual representation of knowledge. Visual representation that done of subject in this case is a form of sensory mathematical imagination. It reinforced the opinion Wibowo \& As'ari (2014) who said sensory mathematical imagination can be seen through appear of the idea based on students perception in solving mathematics problems. In line with that expressed by Currie \& Ravenscroft (2002) that sensory imagination can appear through perception such as stimulus of the problem. Reinforced the opinion Ferrara (2006), which said imagination in learning mathematics as the center of perception and motor activity of students.

Based on the above there are some characteristics of students sensory mathematical imagination that appear in solving mathematical problems, namely appear of the idea based on perception due to stimulus of the problem, 
expound information by analogy according to what people think, sensory mathematical imagination involves body movement activity (sensory motor) and sensory mathematical imagination can be seen through a visual representation of the student in solving mathematics problems.

\section{Conclusion}

The process of sensory mathematical imagination begins from appear of subject perception to determine the length of square. Perception that done of subject appears due to stimulus of the problem. The stimulus is order in the question to determine the length side of each square that meets the image. These stimulus induce subject perception to determine the length side of each square. Through perception appeared the idea for solving mathematics problem. In this case the idea is appear of students in solving mathematics problem is a representation of sensory mathematical imagination. Sensory mathematical imagination can be seen through appear the idea based on students perceptions in solving mathematics problem. This idea can be seen through a visual representation of solving mathematics problem. The visual representation that done of subject in this case is a form of sensory mathematical imagination.

Characteristics of students sensory mathematical imagination who appeared in solving mathematics problem, namely appear of the idea based on perception due to stimulus of the problem, expound information by analogy according to what people think, sensory mathematical imagination involves body movement activity (sensory motor), and sensory mathematical imagination can be seen through a visual representation of the student in solving mathematics problems.

\section{Disclosure statement}

No potential conflict of interest was reported by the authors.

\section{Notes on contributors}

Teguh Wibowo, Magister of Mathematics Education, Doctoral Student State University of Malang, East Java, Indonesia.

Akbar Sutawidjaja, Doctor of Mathematics Education, Professor of the Department Mathematics Education, State University of Malang, East Java, Indonesia.

Abdur Rahman As'ari, Doctor of Instruction Technology, Department of Mathematics Education, State University of Malang, East Java, Indonesia.

I Made Sulandra, Doctor Rerum Naturalium, Department of Mathematics Education, State University of Malang, East Java, Indonesia.

\section{References}

Carroll, M., Goldman, S., Britos, L., Koh, J., Adam, R., and Hornstein, M. (2010). Destination, Imagination and the Fires Within: Design Thinking in a Middle School Classroom. Journal Compilation (C), NSEAD/Blackwell Publishing Ltd.

Chapman, O. (2008). Imagination as a Tool in Mathematics Teacher Education. Journal Mathematics Teacher Education, 11, 83-88.

Creswell, J.W. (2014). Research Design: Qualitative, Quantitaive and Mixed Methods Approaches. California: Saga Publication.

Currie, G. \& Ravenscroft, I. (2002). Recreative Minds: Imagination in Philosophy and Psychology. Oxford: Oxford University Press. 
Ferrara, F. (2006). Remembering and Imagining: Moving back and forth between motion and its representation. Proceedings of the Thirtieth Conference of the International Group for the Psychology of Mathematics Education, (Vol.3, pp.65-72). Prague: Charles University.

Kotsopoulos, D. \& Cordy, M. (2009). Investigating Imagination as a Cognitive Space for Learning Mathematics. Educ Stud Math, 70, 259-274, DOI 10.1007/s 10649-008-9154-0.

Muir, T., Beswick, K., Williamson, J. (2008). "I'm not very good at solving problems": An exploration of students' problem solving behaviours. Journal of Mathematical Behavior, 27, 228-241.

Nemirovsky, R. \& Ferrara, F. (2008). Mathematical Imagination and Embodied Cognition. Journal Educational Studies in Mathematics, 70, 159-174.

Samli, A.C. (2011). From Imagination to Creativity. From Imagination to Innovation: New Product Development for Quality of Life, DOI 10.1007/978-1-4614-0854-3_2, (C) Springer Science + Business Media, LLC.

Solso, R., Maclin, O. \& Maclin, M. (2008). Psikologi Kognitif Edisi Kedelapan. Jakarta: Erlangga.

Swirski, T. (2010). Unleashing the imagination in learning, teaching and assessment: design perspectives, innovative practices and meaning making. Ph.D candidate, Macquarie University.

van Alphen, P. (2011). Imagination as a transformative tool in primary school education. RoSE Research on Steiner Education, 2 (2), ISSN 1891-6511.

Wibowo, T. and As'ari, A.R. (2014). Type Imagination Student Mathematical In Mathematical Problem Solving. Proceedings of the National Seminar on Education Mathematics II. Math P4TK Yogyakarta.

Wilke, J. (2010). Using Imagination in the Math Classroom. Journal of Educational Perspectives, $39(2)$. 